\title{
Editorial
}

\section{Alimentação e Cultura como campo científico}

| Kenneth Rochel de Camargo Jr. |

O tema desta edição, organizado por Shirley Prado, aborda a constituição da Alimentação e Cultura como campo científico em três contextos nacionais distintos. Além da proximidade e das múltiplas interseções desse campo com a Saúde Coletiva, a qualidade e profundidade das reflexões dos artigos temáticos (apresentados à frente por sua organizadora) trazem elementos facilmente generalizáveis para a discussão sobre ciência e saúde.

A seção de temas livres traz um conjunto variado de artigos, que têm em comum, em algum grau, o reexame de temas aparentemente já discutidos, mas em todos os casos apresentando um novo ângulo teórico-metodológico.

Abrindo a seção, Horta e Sena analisam as abordagens e concepções sobre os conceitos de "adolescente" e "jovem" em documentos oficiais, uma importante contribuição para o estudo de políticas públicas nessa área. Segue-se o artigo de Medeiros, que comenta um artigo anteriormente publicado nesta revista, agregando contribuições do referencial lacaniano à discussão sobre formação para a área de Saúde. Alonso relata as relaçóes entre corporalidade e incerteza num grupo de pacientes oncológicos, a partir de um estudo etnográfico realizado em Buenos Aires. No quarto artigo da seção, Heuer retoma Arendt como contribuição para a discussão corrente sobre o biologismo e o mundo biotecnológico, encerrando com uma reflexão sobre a medicina chinesa com base na mesma autora. Por sua vez, González e Ameida buscam, com base em uma revisão histórica, construir uma sistematização sobre as propostas de mudança na formação superior em saúde em nosso país. No artigo seguinte, Souza e Scatena trazem a avaliação de um hospital de Mato Grosso, baseada no método de análise de custo-volume-superávit, como contribuição à necessária melhoria da eficiência dos serviços públicos de saúde. $\mathrm{O}$ artigo de Correa e Moás analisa os critérios jurídicos de determinação das relações parentais, visando a subsidiar a inscrição 
de proposições de parentalidade homossexual no âmbito do direito à vida familiar. Segue-se o texto de O’Dwyer e Mattos, que propõem uma discussão sobre a Teoria da Estruturação como estratégia metodológica que possa dar apoio às tentativas de modificação de práticas no âmbito do SUS. Nascimento explora um fato aparentemente singelo, o ato de lavar as mãos como procedimento higiênico básico na atenção à saúde, buscando compreender a baixa adesão de médicos ao mesmo. Fechando a seção, Silva aborda o desafio representado pelas pessoas em medida de segurança, por meio da descrição e análise do Programa de Atenção Integral ao Louco Infrator, implementado em Goiás.

Esta edição se encerra com a resenha feita por Santos sobre o livro Saúde bucal no Programa Saúde da Familia: sujeitos, saberes e práticas. 